1 Evolutionary factors affecting the cross-species utility of newly developed microsatellite markers in

2 seabirds

3

4

5 YOSHAN MOODLEY ${ }^{1, *}$, JUAN F. MASELLO ${ }^{2}$, THERESA L. COLE ${ }^{2,3}$, LUCIANO CALDERON $^{2}$,

6 GOPI K. MUNIMANDA ${ }^{1}$, MARCO R. THALI ${ }^{4}$, RACHAEL ALDERMAN ${ }^{5}$, RICHARD J.

7 CUTHBERT $^{6}$, MANUEL MARIN $^{7,8}$, MELANIE MASSARO $^{9}$, JOAN NAVARRO $^{10}$, RICHARD A.

8 PHILLIPS ${ }^{11}$, PETER G. RYAN ${ }^{12}$, CRISTIÁN G. SUAZO ${ }^{2}$, YVES CHEREL ${ }^{13}$, HENRI

9 WEIMERSKIRCH ${ }^{13}$ \& PETRA QUILLFELDT ${ }^{2}$

10

11

$12{ }^{1}$ Konrad Lorenz Institute for Ethology, Department of Integrative Biology and Evolution, University

13 of Veterinary Medicine Vienna, Savoyenstr. 1a, A-1160, Vienna, Austria

$14{ }^{2}$ Justus Liebig University Giessen, Department of Animal Ecology \& Systematics, Heinrich-Buff-

15 Ring 38, D-35392, Giessen, Germany

$16{ }^{3}$ Trace and Environmental DNA Laboratory, Department of Environment and Agriculture, Curtin

17 University, Perth, WA 6102, Australia

$18{ }^{4}$ Ecogenics GmbH, Grabenstrasse 11a, 8952, Zurich-Schlieren, Swiss

$19{ }^{5}$ Department of Primary Industries, Parks, Water and Environment, GPO Box 44, Hobart, Tasmania 207001 , Australia

$21{ }^{6}$ Royal Society for the Protection of Birds (RSPB), The Lodge, Sandy, Bedfordshire SG19 2DL, UK

$22{ }^{7}$ Section of Ornithology, Natural History Museum of Los Angeles County, 900 Exposition Boulevard,

23 Los Angeles, CA 90007, USA

$24{ }^{8}$ Feather Link Inc., 1013 Westchester Way, Cincinnati, OH 45244, USA

$25{ }^{9}$ School of Environmental Sciences, Charles Sturt University, PO Box 789, Albury, NSW, 2640, 26 Australia 
$27{ }^{10}$ Department of Conservation Biology, Estación Biológica de Doñana (EBD-CSIC), Avda. Américo 28 Vespucio s/n, Seville 41092, Spain

$29{ }^{11}$ British Antarctic Survey, Natural Environment Research Council, High Cross, Madingley Road, 30 Cambridge CB3 0ET, UK

$31{ }^{12}$ Percy FitzPatrick Institute, DST/NRF Centre of Excellence, University of Cape Town, Rondebosch 327701 , South Africa

$33{ }^{13}$ Centre d'Etudes Biologiques de Chizé, UMR 7372 CNRS-Université de La Rochelle, 79360

$34 \quad$ Villiers-en-Bois, France

35

36 Keywords: cross-species transferability, genetic diversity, microsatellite, null alleles, Pachyptila,

37 Procellariiformes

38

39

$40 \quad{ }^{*}$ Correspondence: Yoshan Moodley, fax +43-1-489-09-15-801; E-mail:

41 yoshan.moodley@vetmeduni.ac.at

42

43

44 Running title: Cross-species utility of microsatellites for seabirds

45 
47 Microsatellite loci are ideal for testing hypotheses relating to genetic segregation at fine spatio-

48 temporal scales. They are also conserved among closely related species, making them potentially

49 useful for clarifying interspecific relationships between recently diverged taxa. However, mutations at

50 primer binding sites may lead to increased non-amplification, or disruptions that may lead to

51 decreased polymorphism in non-target species. Furthermore, high mutation rates and constraints on

52 allele size may also lead, with evolutionary time, to an increase in convergently evolved allele size

53 classes, biasing measures of interspecific genetic differentiation. Here, we used next-generation

54 sequencing to develop microsatellite markers from a shotgun genome sequence of the sub-Antarctic

55 seabird, the thin-billed prion (Pachyptila belcheri), that we tested for cross-species amplification in

56 other Pachyptila and related sub-Antarctic species. We found that heterozygosity decreased and the

57 proportion of non-amplifying loci increased with phylogenetic distance from the target species.

58 Surprisingly, we found that species trees estimated from interspecific $F_{\text {ST }}$ provided better

59 approximations of mtDNA relationships among the studied species than those estimated using $D_{\mathrm{C}}$,

60 even though $F_{\mathrm{ST}}$ was more affected by null alleles. We observed a significantly non-linear second

61 order polynomial relationship between microsatellite and mtDNA distances. We propose that the loss

62 of linearity with increasing mtDNA distance stems from an increasing proportion of homoplastic allele

63 size classes that are identical in state, but not identical by descent. Therefore, despite high cross-

64 species amplification success and high polymorphism among the closely related Pachyptila species,

65 we caution against the use of microsatellites in phylogenetic inference among distantly related taxa. 
69 Two-thirds of our planet is covered by sea, and albatrosses, petrels and storm-petrels (Aves,

70 Procellariiformes) are, par excellence, the seabirds of the open ocean, only coming ashore to breed, 71 usually on remote islands (Brooke 2004). This highly mobile group of seabirds could theoretically maintain high levels of gene flow, but strong philopatry to breeding islands observed in some species

73 (Ovenden et al. 1991, Steeves et al. 2005, Bicknell et al. 2012) may lead to pronounced genetic

74 differentiation between populations. Our understanding of gene flow and genetic structure in petrels 75 has improved considerably in recent years (Smith et al. 2007, Lawrence et al. 2008, Gangloff et al. 76 2012, Wiley et al. 2012, Kerr \& Dove 2013) but remains poor for the diverse and often widespread species that breed on sub-Antarctic islands.

Petrels (Procellariidae) of the genus Pachyptila, the prions, are ideal monitors of ocean productivity as they feed mainly on zooplankton, which responds rapidly to changing environmental conditions (Hunt et al. 1992, Bocher et al. 2001, Cherel et al. 2002, Quillfeldt et al. 2007, 2008).

Prions are highly mobile and have a wide distribution in sub-Antarctic waters (Onley \& Scofield 2007). Detailed studies on diet, breeding biology and behavioural ecology have been published for several prion species (Strange 1980, Bretagnolle et al. 1990, Liddle 1994, Ridoux 1994, Reid et al. 1999, Cherel et al. 2002, Quillfeldt et al. 2003, 2007, 2008, Navarro et al. 2013). Much less was known about distributions at-sea, particularly during the nonbreeding season. However, recent stable isotope and tracking studies indicate considerable ecological segregation among populations breeding in the Atlantic and Indian sectors of the Southern Ocean (Cherel et al. 2002, 2006, Quillfeldt et al. 2010, 2013). This spatial and temporal segregation could potentially lead to population differentiation, with consequences for taxonomy and conservation status.

Prions are generally clustered into 2 groups, the species with, or without, palatal lamellae, and hence filtering apparatus (Prince \& Morgan 1987). The former (the so-called "whale birds") includes the Antarctic prion Pachyptila desolata, Salvin's prion P. salvini and broad-billed prion P. vittata, and the latter, the thin-billed prion $P$. belcheri, fairy prion $P$. turtur and fulmar prion P. crassirostris. As 
94 yet, there are no phylogeographic studies of any prion species, and only scattered genetic information 95 exists (e.g. Ovenden et al. 1991). Nor is there agreement regarding the number of prion species or 96 their genetic relationships (see Brooke 2004, Penhallurick \& Wink 2004, Rheindt \& Austin 2005, 97 Onley \& Scofield 2007). Using enzyme electrophoresis, Barrowclough et al. (1981) concluded that Antarctic prions were closely related to blue petrels Halobaena caerulea, and Viot et al. (1993) that Antarctic prions, thin-billed prions and Salvin's prions were very closely related. The low variation at 100 the mitochondrial cytochrome $b$ gene also suggests that Antarctic prions, thin-billed prions and blue 101 petrels are closely related species (Nunn \& Stanley 1998). Based on the same locus, Penhallurick \& 102 Wink (2004) invoked the multidimensional biological species concept to suggest that all prions 103 represent just two species. However, this last study was heavily criticised (Rheindt \& Austin 2005). 104 Consequently, taxonomic authorities and field guides still follow the scheme outlined by Bretagnolle et al. (1990) which concluded from the combination of morphometrics, breeding biology, genetics and

106 calls, that Antarctic, Salvin's, thin-billed, and fairy prions were distinct but closely related species.

107 The recent description of distinct thin- and broad-billed morphs, within broad-billed prions that also 108 show strong differences in breeding phenology at Gough Island raises further questions regarding 109 intra- and interspecific relationships of this group (Ryan et al. 2014). More genetic data from the many 110 populations of prions that breed in the sub-Antarctic could potentially shed important light on these 111 open questions.

112 Microsatellite loci are powerful tools in population and evolutionary genetics that could 113 provide the resolution for detailed analyses of several aspects of prion biology. Given their high 114 mutation rate, they are ideal for testing hypotheses relating to fine-scale spatio-temporal segregation 115 and for the estimation of demographic parameters such as gene flow, effective population size and 116 genetic variability (Bruford \& Wayne 1993, Sunnocks 2000). They are also conserved among closely117 related species (Moore et al. 1991) making them potentially useful for clarifying interspecific genetic 118 relationships between recently diverged taxa (e.g. Dawson et al. 2010), although their high mutation 119 rate means that loci developed for one species may not always be useful for others. This is because 120 mutations at primer binding sites may lead to increased non-amplification (Moodley et al. 2006) or 
121 disruptions within tandemly repeated elements may lead to a reduced level of observed polymorphism

122 in the non-target species (Garza et al. 1995, Primmer et al. 2005). The taxa of interest must therefore

123 be closely related in order to maximise utility and offset the costs of microsatellite development.

124 Hence, the testing of newly developed microsatellite loci for cross-species utility has become fairly 125 standard practice (Li et al. 2003, Bried et al. 2008, Dawson et al. 2010, Jan et al. 2012, Huang et al.

126 2014); however, few surveys have reported statistical trends in their multispecies data sets.

127 Here, we used next-generation sequencing technology to develop a set of 26 polymorphic

128 microsatellite markers from a shotgun genome sequence of the thin-billed prion in order to test for

129 genetic structure among the different populations of this species and to provide an accurate estimation

130 of demographic parameters. We also tested these microsatellite loci for cross-species amplification in

131 other prions, the closely related blue petrel (all Procellariiformes, Procellariidae), and the more

132 distantly related Wilson's storm petrel Oceanites oceanicus (Procellariiformes, Hydrobatidae). While

133 prion species appear to be very closely related, we predict, nevertheless, that average observed

134 microsatellite genetic diversity will decrease, whereas the number of non-amplifying alleles will

135 increase, with increasing phylogenetic distance from the species of origin (thin-billed prion). As any

136 increase in null allele frequency could bias the estimation of essential population parameters in

137 phylogeographic studies (e.g. Astanei et al. 2005, Wulff et al. 2012, McCormack et al. 2013) and

138 perhaps even alter phylogenetic relationships, we corrected our raw data for null alleles using methods

139 developed by Chapuis \& Estoup (2007). This allowed for a comparison of the effect of null alleles on

140 levels of interspecific differentiation.

141 Lastly, high microsatellite mutation rates coupled with mutational limits on allele sizes

142 (Ostrander et al. 1993, Bowcock et al. 1994) increase the probability of convergent evolution of allele

143 size classes. Given this highly homoplastic scenario, population parameters and evolutionary

144 hypotheses inferred under the assumption that alleles of the same size share a most recent common

145 ancestor (i.e. are identical by descent) could be biased, even in comparisons between sister taxa

146 (Paetkau et al. 1997). We expect, therefore, that microsatellite genetic distance between species will

147 be biased to lower values as the evolutionary time separating species increases. 


\section{Molecular methods}

151 Between 2010-2012, samples (all from adults) from 77 thin-billed prions, 79 Antarctic prions, 118 broad-billed prions, 18 Salvin's prions, 35 fairy prions, 99 blue petrels and 6 Wilson's storm-petrels were obtained in breeding colonies located on sub-Antarctic island groups (Noir, Diego Ramirez,

154 Falkland/Malvinas, South Georgia, Tristan da Cunha, Gough, Marion, Kerguelen, Macquarie, and

155 Chatham). Genomic DNA was obtained from different sample types: blood in ethanol (Gough and 156 Diego Ramirez), blood in Queens's lysis buffer (Kerguelen and Falkland/Malvinas), blood on FTA 157 classic cards (Whatman International Ltd., Maidstone, UK; South Georgia and Chatham), muscle in 158 ethanol (Macquarie, Gough, Tristan da Cunha and Noir) and feather quills (Marion, Tristan da Cunha and Falkland/Malvinas). DNA was extracted from blood $(n=313)$, feather quills $(n=101)$ or muscle tissue ( $n=51)$ using the Qiagen DNeasy ${ }^{\circledR}$ Tissue kit (Qiagen, Germany). DNA quantity and quality was determined by UV spectrophotometry using a NanoDrop 1000 Spectrophotometer, and all sampled were standardized to a final concentration of $10 \mathrm{ng} / \mu \mathrm{l}$. Microsatellite-containing genomic sequences were isolated by ecogenics $\mathrm{GmbH}$ (Switzerland)

164 from a 1:1 pool of two thin-billed prion individuals from Mayes Island in the Kerguelen Archipelago 165 using a modified high-throughput genomic sequencing approach (Abdelkrim et al. 2009). Genomic DNA was nebulised to 300-800bp and ligated into an ssDNA library. These size-selected fragments

167 were then enriched for tandemly repeated element content by using magnetic streptavidin beads and 168 biotin-labelled CT and GT repeat oligonucleotides. This enriched shotgun library was then sequenced 169 on a Roche 454 next generation platform using the GS-FLX titanium reagents. Resulting sequence 170 reads were passed through quality filters and scanned for microsatellite repeats, from the conserved 171 flanking regions of which primer pairs were designed using Primer 3 (Untergasser et al. 2012). After initial testing for amplification and polymorphism, microsatellite loci were visualised in 
174 Schuelke (2000). PCR was then performed in a final volume of $10 \mu$ including: $1 \times$ Qiagen PCR

175 buffer, $2 \mathrm{mM}$ dNTPs, $2 \mu \mathrm{M}$ M13-tailed forward primer, $2 \mu \mathrm{M}$ reverse primer, $2 \mu \mathrm{M}$ of universal M13

176 primer 5'-end labelled, 0.5 U Hotstar Taq (Qiagen) and $10 \mathrm{ng}$ template. The PCR program comprised

177 an initial denaturation step of $95^{\circ} \mathrm{C}$ for $15 \mathrm{~min}$, the cycling parameters were: 30 cycles at $95^{\circ} \mathrm{C}$ for 30

$178 \mathrm{~s}$, an annealing temperature of $56^{\circ} \mathrm{C}$ for $45 \mathrm{~s}, 72^{\circ} \mathrm{C}$ for $45 \mathrm{~s}, 8$ cycles of $95^{\circ} \mathrm{C}$ for $30 \mathrm{~s}, 53^{\circ} \mathrm{C}$ for $45 \mathrm{~s}$,

$17972^{\circ} \mathrm{C}$ for $45 \mathrm{~s}$, and a final extension step of $72^{\circ} \mathrm{C}$ for $30 \mathrm{~min}$. PCR products were visualised on a $1.5 \%$

180 agarose gel to confirm successful amplification and to examine negative controls. Products were run

181 on a AB $3130 x l$ genetic analyser along with a ROX size-standard. We repeated all PCR reactions for

182 individuals that failed to amplify at $>4$ loci and for those loci with $>10 \%$ missing data.

183 We used an $880 \mathrm{bp}$ fragment of the mitochondrial cytochrome $b$ gene to estimate the

184 phylogenetic relationships among the seven taxa in our data set, since two of our hypotheses required

185 an independent estimate of interspecific phylogenetic distance. While we do not believe that mtDNA

186 distances are unbiased, we do feel that its slower mutation rate, relative to that of microsatellites,

187 would ensure its linearity among the seven species on our comparison. Furthermore, cytochrome $b$ has

188 been used previously to successfully infer relatedness among a much broader sample of

189 Procellariiformes (Nunn \& Stanley 1998), and previous morphological and behavioural analyses

190 (Bretagnolle et al. 1990) did not specifically quantify interspecific distances among the species in our

191 study. Generic avian cytochrome $b$ primers (eg. Patterson et al. 2011) were problematic for some

192 samples. Therefore, we designed specific primers (CytB_Pri_F: 5'-CTAGCTATACACTACACCGC-

193 3' and

194 CytB_Pri_R: 5'-CTAGTTGGCCGATGATGATG-3') for our study group from an alignment of those

195 samples that we successfully sequenced. PCRs were conducted in $20 \mu 1$ reaction volumes containing

$196100 \mathrm{ng}$ DNA template, $10 \mathrm{mM}$ of each primer, $10 \mathrm{mM}$ dNTPs (Roth, Karlsruhe), $2 \mathrm{mM} \mathrm{MgCl}, 5 \mathrm{U}$

197 Thermus aquaticus polymerase (BioLabs Taq DNA polymerase) in a 1x PCR reaction buffer.

198 Thermocycling included initial denaturation at $94^{\circ} \mathrm{C}$ for 2 minutes, 30 cycles of denaturation at $94^{\circ} \mathrm{C}$

199 for $30 \mathrm{~s}$, annealing at $60^{\circ} \mathrm{C}$ for $45 \mathrm{~s}$ and extension at $72^{\circ} \mathrm{C}$ for $1 \mathrm{~min}$, followed by a final extension step

200 of $5 \mathrm{~min}$ at $72^{\circ} \mathrm{C}$. Products were purified of excess primers and dNTPs using exonuclease-shrimp 
alkaline phosphatase (Fermentas Life Sciences following the manufacturer's specifications). PCR

202 products were then sequenced in both directions using Big Dye chemistry (Applied Biosystems) and

203 run on an AB 3130xl genetic analyser (Applied Biosystems). Resulting sequences were assembled and 204 aligned in CLC Main Workbench ${ }^{\circledR}$ 6.9.2.

Data analyses

207 Genotypes were assigned with GeneMarker 1.85 (SoftGenetics LLC, State College, PA, USA). 20\%

208 of the samples were re-scored by a separate individual, with a resulting error rate of $<5 \%$. The 209 probability of deviation from Hardy-Weinberg equilibrium (HWE) and non-random association of 210 loci was calculated for each locus/species combination using GENEPOP (Raymond \& Rousset 1995;

211 Tables 1 and 2). Measures of genetic diversity (number of alleles per locus $(A)$, observed 212 heterozygosity $\left(H_{o}\right)$ and expected heterozygosity $\left(H_{e}\right)$ ) were estimated in Cervus 3.0.3 (Kalinowski et 213 al. 2007) and MSA 4.05 (Dieringer \& Schlötterer 2003). The inbreeding coefficient $\left(F_{I S}\right)$ and its 214 significance were estimated with GENEPOP (Raymond \& Rousset 1995). Null allele frequencies (F 215 null) per locus and species were obtained using FreeNA (Chapuis \& Estoup 2007). Phylogenetic distances between species at the cytochrome $b$ gene were calculated using the 217 maximum likelihood in MEGA (Tamura et al. 2013). We reconstructed the mitochondrial species 218 phylogeny by firstly determining the most suitable substitution model for the cytochrome $b$ sequence 219 data using the Akaike information criteria (AIC) in JModeltest 2 (Darriba et al. 2012), then set the 220 model parameters to the general time reversible (GTR) model with gamma substitution rate 221 heterogeneity estimated from the data using four rate categories. We examined the cross-species utility of our isolated microsatellite loci by plotting genetic 223 diversity $\left(H_{o}\right)$ and the proportion of missing data (non-amplifying loci after 3x repeat PCRs, with standardised DNA quantity and quality) in each species against phylogenetic (mtDNA, cytochrome $b$ )

225 p-distances, calculated in MEGA (Table S1). We also performed this regression separately for three 226 different phylogenetic groupings: Group 1: all seven species; Group 2: Halobaena and Pachyptila 227 only; Group 3: Pachyptila species only. For a more detailed analysis of these relationships, we used a 
228 generalized linear model (GLM, implemented in R, R Development Core Team 2014), to test the

229 effect of phylogenetic distance (as a covariate) and locus (as a factor) on both observed heterozygosity

230 and the proportion of missing data in each of the three species groupings above. A GLM could not be

231 used to test for the effect of phylogenetic distance and locus on null allele frequencies due to a large

232 amount of missing data in Wilson's storm-petrels.

233 The frequency of null alleles was calculated in our dataset using FreeNA (Chapuis \& Estoup,

234 2007). This method estimates the frequency of null alleles from data sets simulated to contain and not

235 contain null alleles. Then it uses the expectation-maximisation (EM) algorithm of Dempster et al.

236 (1977) to adjust homozygote allele frequencies based on true and false homozygote counts, resulting

237 in the estimation of the null allele frequency. Population differentiation indices can then be calculated

238 including null alleles (INA) and also only on the visible allele sizes, thus, excluding null alleles

239 (ENA). To determine the effect of null alleles on cross-species comparisons, we calculated pair-wise

$240 \quad F_{\mathrm{ST}}$ (Wright 1943) and $D_{\mathrm{C}}$ (genetic distance of Cavalli-Sforza \& Edwards, 1967) between species

241 using INA and ENA data sets. We re-constructed UPGMA species trees from these triangular $F_{\mathrm{ST}}$ and

$242 D_{\mathrm{C}}$ matrices, using MEGA 6.06 (Tamura et al. 2013).

243 We investigated the effect of high mutation rates and constraints on allele size on

244 microsatellite genetic distance by observing the change in the slope of pair-wise Mantel regressions

245 performed on the same three phylogenetic data groupings used in Figure 1. As interspecific

246 microsatellite distance, we used INA and ENA triangular matrices of both $F_{\mathrm{ST}}$ and $D_{\mathrm{C}}$ and checked

247 their linearity against the matrix of pair-wise maximum likelihood cytochrome $b$ distances calculated

248 previously (Table S1). All Mantel regressions were calculated in GenAlEx 6.5 (Peakall \& Smouse

249 2012). To formally test the hypothesis that $F_{\mathrm{ST}}$ and $D_{\mathrm{C}}$ microsatellite distances were non-linearly

250 related to mtDNA distance, we fitted the data (INA and ENA for all species) with both linear and

251 polynomial functions, and performed model testing within a GLM framework in R using the Akaike

252 information criterion (AIC). 
255 Shotgun 454 sequencing of two pooled thin-billed prion genomes resulted in 22,220 reads after quality 256 filtering, with an average read-length of $177 \mathrm{bp}$ (total of $3.9 \mathrm{Mb}$ ). Of these, $517(2.3 \%)$ contained 257 microsatellite repeat elements with tetra- or trinucleotides of at least six repeat units, or dinucleotides 258 of at least 10 repeat units. Suitable primer design was possible in 166 reads. We tested 36 of these 259 primer pairs for cross-species amplification and polymorphism among four other unrelated Mayes Island $P$. belcheri and three individuals from the closely related $P$. desolata from Verte Island, also in

261 the Kerguelen Archipelago. Twenty-six loci were identified as polymorphic in the target species, 262 showing clear amplification profiles and reliable amplification in both species tested. We further tested 263 the reliability of amplification and genotypic disequilibrium in a larger set of 77 thin-billed prions 264 from across the breeding range (Kerguelen, Falkland/Malvinas, and Isla Noir in southern Chile). 265 Among populations of the target species, the number of alleles $(A)$ per locus ranged from 5 to 48 , the 266 observed heterozygosity $\left(H_{o}\right)$ from 0.325 to 0.880 , and the expected heterozygosity $\left(H_{e}\right)$ from 0.493 to 2670.972 (Table 1). Cross-species amplification was successful for most primer pairs in Antarctic prions, 268 broad-billed prions, fairy prions, Salvin's prions, and blue petrels, whereas only a third of pairs 269 worked successfully that included the distantly related Wilson's storm petrel (Table 2). One of the 26 loci screened (Pacbel_00829) was found to be in significant linkage equilibrium with locus Pacbel_03731 and locus Pacbel_08509, but the latter two loci appeared statistically unlinked. We 272 therefore removed locus Pacbel_00829 from further analyses. The mean observed heterozygosity decreased in other prion species, blue petrel and Wilson's

274 storm petrel with increasing mtDNA phylogenetic p-distance (Table S1) from the thin-billed prion 275 (Group 1 including all species, $\mathrm{f}=0.6-2.7^{*} \mathrm{x}, R^{2}=0.21, P<0.001$; Group 2 Pachyptila and Halobaena, $\mathrm{f}=0.6-2.0^{*} \mathrm{x}, R^{2}=0.07, P=0.001 ;$ Group 3 only Pachyptila, $\mathrm{f}=0.7-8.4^{*} \mathrm{x}, R^{2}=0.25, P$

$277<0.001$; Table S1, Fig. 1). This tendency was also consistent for most loci in a generalized linear 278 model (GLM), using phylogenetic distance as covariate and locus as factor (Group 1 including all 279 species, effect of distance: $F=2.189, d f=1, P<0.001$, effect of locus: $F=3.046, d f=24, P<0.001$; 280 Group 2 Pachyptila and Halobaena, effect of distance: $F=0.468, d f=1, P<0.001$, effect of locus: $F$ 
$=2.843, d f=24, P<0.001$; Group 3 only Pachyptila, effect of distance: $F=1.207, d f=1, P<0.001$,

282 effect of locus: $F=2.106, d f=24, P<0.001$ ). The proportion of missing data increased slightly

283 (Group 1, $\mathrm{f}=0.1+1.0 * \mathrm{x}, R^{2}=0.04, P=0.006$; Group 2, $\mathrm{f}=0.1+0.4 * \mathrm{x}, R^{2}=0.004, P=0.473$; Group

$2843, \mathrm{f}=0.01+8.6^{*} \mathrm{x}, R^{2}=0.31, P<0.001$ ) with phylogenetic distance from thin-billed prion (Fig. 1),

285 and a GLM confirmed this trend for individual loci (Group 1, effect of distance: $F=0.361, d f=1, P=$

286 0.003, effect of locus: $F=1.296, d f=24, P=0.134$; Group 2, effect of distance: $F=0.017, d f=1, P=$

287 0.428, effect of locus: $F=0.805, d f=24, P=0.191$; Group 3, effect of distance: $F=1.24, d f=1, P<$

288 0.001, effect of locus: $F=0.911, d f=24, P<0.001$ ).

The average frequency of null alleles among the loci and species in our total data set was low $(0.076 \pm 0.085)$, although values for some loci/species combinations were quite high (0.364). INA and ENA species trees constructed from pair-wise species $F_{\mathrm{ST}}$ (Fig. 2A) and $D_{\mathrm{C}}$ (Fig. 2B) values (Table S2) were superimposed onto each other for comparison. $F_{\mathrm{ST}}$ values tended to decrease more than $D_{\mathrm{C}}$ when corrected for the presence of null alleles (black relative to grey branches, Fig. 2A/B). This correction did not alter the relationships between taxa for either measure of genetic differentiation. Both trees were compared for topological congruence with the mtDNA phylogeny of the cytochrome $b$ gene (Fig. 2C). As with the mtDNA phylogeny, $F_{\mathrm{ST}}$ and $D_{\mathrm{C}}$ trees separated the genus Pachyptila from outgroup genera Halobaena and Oceanites, and positioned the fairy prions basally within the Pachyptila clade. All trees differed regarding the placement of the most derived Pachyptila taxa. $F_{\mathrm{ST}}$ more closely approximated the mtDNA phylogeny in that $P$. desolata and $P$. salvini were sister taxa, but they differed with respect to the placement of $P$. belcheri and $P$. vittata (Figure 2).

Mantel regressions (Fig. 3) indicated that a large proportion of DNA sequence variance in the cytochrome $b$ data could be significantly explained by the multilocus microsatellite distance statistics $F_{\mathrm{ST}}$ and $D_{\mathrm{C}}(R \mathrm{xy}>0.9$ in all cases, see Fig. 3$)$. However, the relationship between microsatellite and mtDNA distance values changed markedly among the three groups of species tested, and depended on which species were included. The slopes of the regressions including all species (Group 1) were

306 lowest and increased incrementally as more phylogenetically similar taxa (Group 2, only Pachyptila 307 and Halobaena; Group 3, only Pachyptila species) were grouped together. This effect was more 
308 pronounced for $D_{\mathrm{C}}$, with shallower gradients differentiating $F_{\mathrm{ST}}$ regressions. Microsatellite distance

309 statistics calculated including null alleles almost always resulted in a steeper gradient than ENA

310 values, but this difference was smallest in the group that contained all seven species.

311 We tested the hypothesis that microsatellite distances were non-linear with evolutionary time

312 by model fitting. We found that linear functions provided a closer fit to $F_{\mathrm{ST}}$ distances than to $D_{\mathrm{C}}$

313 distances, but that second order (quadratic) polynomials provided a significantly better fit than linear

314 functions for both distance statistics (Table 3).

\section{Discussion}

\section{$317 \quad$ Non-amplification and null alleles}

318 We amplified microsatellite loci in 432 individual samples in seven species of petrels. Concordant 319 with expectation, we found that genetic diversity decreased, and the proportion of non-amplifying 320 (missing) data, increased with phylogenetic distance from the target species. Although global 321 regressions (Group 1) as well as groups containing Halobaena and Pachyptila species (Group 2) and 322 Pachyptila species (Group 3) were highly significant in most cases, the trend was not observed in all

323 loci, resulting in shallow regression gradients. Nevertheless, this confirmed our expectation that 324 genetic diversity decreases and missing data increases with evolutionary distance from the target 325 species and is compatible with other studies that show increases in non-amplification and decline in 326 polymorphism (e.g. Li et al. 2003, Primmer et al. 2005, Bried et al. 2008, Dawson et al. 2010, Jan et 327 al. 2012).

328 The average frequency of null alleles in our data set was low, and therefore correcting allele 329 frequencies for the presence of null alleles resulted in no change to overall species tree topologies but 330 decreased $F_{\text {ST }}$ branch lengths (Fig. 2). $D_{\mathrm{C}}$ branch lengths, on the other hand, differed much less 331 between corrected and uncorrected data sets, implying that this statistic is more robust to the presence 332 of null alleles. 
335 We found that species trees estimated from interspecific microsatellite data were largely congruent

336 with mtDNA relationships among the studied species, with $F_{\text {Sт }}$ providing a slightly better

337 approximation than $D_{\mathrm{C}}$ distances. This is a surprising result, since $F_{\mathrm{ST}}$ is a fixation index, and as such

338 does not satisfy the triangle inequality as would true distance measures like $D_{\mathrm{C}}$. Our data also showed

339 the inherent problem posed by null alleles in the resolution of interspecific branch lengths, which

340 affected $F_{\text {ST }}$ more than $D_{\mathrm{C}}$ (Figs. 2A, B). Furthermore, $F_{\mathrm{ST}}$ has often been criticised for inaccurately

341 estimating population differentiation when genetic variation is high (Charlesworth 1998, Balloux \&

342 Lugon-Moulin 2002, Carreras-Carbonell et al. 2006, Jost 2008). Nevertheless, $F_{\mathrm{ST}}$ is perhaps the most

343 reported statistic in population and evolutionary genetics. These comparisons with the cytochrome $b$

344 phylogeny, however, do not account for potential biases in mtDNA itself, nor for differences in tree-

345 building algorithms used for microsatellite (UPGMA) and mtDNA data (maximum likelihood).

346 Therefore, we stress the need for a more thorough reappraisal of the phylogenetic relationships among

347 the prions, using multiple but more slowly evolving nuclear intronic gene sequences.

Linearity of microsatellite genetic distances

The high proportion of explained variation in Mantel regressions of microsatellite and mtDNA genetic distance implies that variation was similarly distributed between the both microsatellite and mitochondrial data sets. However, when regression analyses of the three groups of varying species

353 diversity imposed a linear relationship between microsatellite and mtDNA distance, the slope of the

354 regression changed considerably, suggesting that the true relationship was non-linear. Instead, at lower

355 distance values (e.g. among congeners; Group 3), the relationship appears linear, but microsatellite

356 distance gradually reaches a plateau with increasing mtDNA distance (Fig. 3A, B, Groups 1 and 2), 357 implying that the latter statistic is a better estimator of relationships among distantly related taxa. We 358 tested the hypothesis that microsatellite distances are not linear with evolutionary distance by fitting 359 both linear and polynomial functions to the $F_{\mathrm{ST}}$ and $D_{\mathrm{C}}$ data and found that in both cases a quadratic 360 function best fitted the data (Table 3). 
Interestingly, $F_{\mathrm{ST}}$ appeared to remain linear for longer than $D_{\mathrm{C}}$, especially when corrected for

362 the presence of null alleles (see higher $P$ values, Table 3 ). While this suggests that $F_{\mathrm{ST}}$ might be more

363 useful at higher phylogenetic levels, its usefulness is compromised by its higher variance compared to

$364 D_{\mathrm{C}}$. Because neither microsatellite distance measure maintained linearity in pairwise intergeneric

365 comparisons, we recommend that analyses of genetic differentiation restrict $F_{\mathrm{ST}}$ and $D_{\mathrm{C}}$ to studies in

366 which the target species is closely related to the species from which the markers were developed. In

367 either case, ENA correction for null alleles is essential.

368 Despite high mutation rates of microsatellites, simulations indicate that measures of genetic

369 differentiation will remain linear much longer without constraints in allele size (Nauta \& Weissing

370 1996). Therefore, we propose that the non-linearity we observed at the intergeneric level is a natural

371 consequence of constrained microsatellite allele size that leads to an increase in the number of

372 convergently evolved allele size classes that, while identical in state, are no longer identical by descent

373 in intergeneric pairwise comparisons. Estoup et al. (2002) suggested that at the intraspecific level, the

374 high mutation rates of microsatellites will compensate for the inevitable convergent evolution of some

375 allele classes, while Paetkau et al. (1997) detected a loss of linearity among closely related sister taxa

376 (brown bear Ursus arctos and polar bear U. maritimus). Given that variation in our set of

377 microsatellites remains linear within the genus Pachyptila, perhaps because of a slightly lower

378 mutation rate, or a slightly larger maximum repeat size, we are confident that population genetic and

379 demographic analyses at this level will not be compromised by constraints in allele size.

\section{Conclusions}

382 We show here that a panel of 25 microsatellite loci developed using next generation sequencing of a

383 thin-billed prion shotgun library may be applied in studies of molecular ecology among congeners;

384 however, this approach may result in a greater proportion of null alleles and lower amounts of genetic

385 diversity in the non-target species. Genetic diversities therefore may not be directly comparable

386 between species, despite the use of the same conserved microsatellite markers. In addition, the

387 contrasting results from the two measures of differentiation lead us to discourage the use of these 
388 microsatellites in phylogenetic reconstruction beyond the genus level, as even at that level this may be 389 associated with high variance.

\section{Acknowledgements}

394 The work was funded by a grant provided by the German Science Foundation DFG (Qu 148/5). We 395 would like to thank the New Island Conservation Trust with assistance from Ian, Maria and Georgina 396 Strange, and Benno H. Lüthi, Klemens Pütz and Gerhard Meyer from the Antarctic Research Trust, 397 for crucial support during the fieldwork. We extend special thanks to Ruth Brown for her fieldwork 398 support at Bird Island (South Georgia) and to Jaime A. Cursach for his assistance during fieldwork at 399 Diego Ramirez (Chile). We thank Antje Schreiner for help with the lab work.

400

401

402

403

\section{References}

Abdelkrim J, Robertson B, Stanton J, Gemmell N (2009) Fast, cost-effective development of species-

404 specific microsatellite markers by genomic sequencing. BioTechniques 46, 185-192.

405 Astanei I, Gosling E, Wilson JIM, Powell E (2005) Genetic variability and phylogeography of the

406 invasive zebra mussel, Dreissena polymorpha (Pallas). Molecular Ecology 14, 1655-1666.

407 Balloux F, Lugon-Moulin N (2002) The estimation of population differentiation with microsatellite 408 markers. Molecular Ecology 11, 155-165.

409 Barrowclough GF, Corbin KW, Zink RM (1981) Genetic differentiation in the Procellariiformes. Comparative Biochemistry and Physiology Part B: Comparative Biochemistry 69, 629-632.

411 Bicknell A, Knight M, Bilton D, et al. (2012) Population genetic structure and long-distance dispersal among seabird populations: Implications for colony persistence. Molecular Ecology 21, 2863-2876.

413 Bocher P, Cherel Y, Labat JP, et al. (2001) Amphipod-based food web: Themisto gaudichaudii caught 414 in nets and by seabirds in Kerguelen waters, southern Indian Ocean. Marine Ecology Progress 
Series 223, 261-276.

416 Bowcock A, Ruiz-Linares A, Tomfohrde J, et al. (1994) High resolution of human evolutionary trees 417 with polymorphic microsatellites. Nature 368, 455-457.

418 Bretagnolle V, Zotier R, Jouventin P (1990) Comparative population biology of four prions (Genus 419 Pachyptila) from the Indian Ocean and consequences for their taxonomic status. Auk 107, 305-316. 420 Bried J, Dubois MP, Jouventin P, Santos RS (2008) Eleven polymorphic microsatellite markers in Cory's shearwater, Calonectris diomedea, and cross-species amplification on threatened Procellariiformes. Molecular Ecology Resources 8, 602-604.

Brooke M (2004) Albatrosses and petrels across the world. Oxford University Press, Oxford.

Bruford MW, Wayne RK (1993) Microsatellites and their application to population genetic studies. Current Opinion in Genetics \& Development 3, 939-943.

Carreras-Carbonell J, Macpherson E, Pascual M (2006) Population structure within and between subspecies of the Mediterranean triplefin fish Tripterygion delaisi revealed by highly polymorphic microsatellite loci. Molecular Ecology 15, 3527-3539.

Cavalli-Sforza LL, Edwards AW (1967) Phylogenetic analysis. Models and estimation procedures. American Journal of Human Genetics

19, 233-257.

Chapuis M-P, Estoup A (2007) Microsatellite null alleles and estimation of population differentiation. Molecular Biology and Evolution 24, 621-631.

Charlesworth B (1998) Measures of divergence between populations and the effect of forces that reduce variability. Molecular Biology and Evolution 15, 538-543.

Cherel Y, Bocher P, de Broyer C, Hobson KA (2002) Food and feeding ecology of the sympatric thinbilled Pachyptila belcheri and Antarctic P. desolata prions at Iles Kerguelen, Southern Indian Ocean. Marine Ecology Progress Series 228, 263-281.

438 Cherel Y, Phillips RA, Hobson KA, McGill R (2006) Stable isotope evidence of diverse speciesspecific and individual wintering strategies in seabirds. Biology Letters 2, 301-303.

440 Darriba D, Taboada GL, Doallo R, Posada D (2012) jModelTest 2: more models, new heuristics and 441 parallel computing. Nature Methods 9, 772-772. 
442 Dawson DA, Horsburgh GJ, Küpper C, et al. (2010) New methods to identify conserved microsatellite 443 loci and develop primer sets of high cross-species utility - as demonstrated for birds. Molecular 444 Ecology Resources 10, 475-494.

445 Dempster AP, Laird NM, Rubin DB (1977) Maximum likelihood from incomplete data via the EM 446 algorithm. Journal of the Royal statistical Society 39, 1-38.

447 Dieringer D, Schlötterer C (2003) Microsatellite analyser (MSA): a platform independent analysis tool 448 for large microsatellite data sets. Molecular Ecology Notes 3, 167-169.

449 Estoup A, Jarne P, Cornuet J-M (2002) Homoplasy and mutation model at microsatellite loci and their consequences for population genetics analysis. Molecular Ecology 11, 1591-1604.

Gangloff B, Shirihai H, Watling D, et al. (2012) The complete phylogeny of Pseudobulweria, the most endangered seabird genus: systematics, species status and conservation implications. Conservation Genetics 13, 39-52.

Garza JC, Slatkin M, Freimer NB (1995) Microsatellite allele frequencies in humans and chimpanzees, with implications for constraints on allele size. Molecular Biology and Evolution 12, 594-603.

Huang D, Zhang Y, Jin M, et al. (2014) Characterization and high cross-species transferability of microsatellite markers from the floral transcriptome of Aspidistra saxicola (Asparagaceae). Molecular Ecology Resources 14, 569-577.

Hunt GL, Priddle J, Whitehouse MJ, Veit RR, Heywood RB (1992) Changes in Seabird Species Abundance Near South Georgia During A Period of Rapid Change in Sea-Surface Temperature. Antarctic Science 4, 15-22. microsatellite markers of high cross-species utility in bat species (Vespertilionidae, Chiroptera, Mammalia). Molecular Ecology Resources 12, 532-548.

Jost LOU (2008) $\mathrm{G}_{\mathrm{ST}}$ and its relatives do not measure differentiation. Molecular Ecology 17, 4015-

467 Kalinowski ST, Taper ML, Marshall TC (2007) Revising how the computer program cervus 468 accommodates genotyping error increases success in paternity assignment. Molecular Ecology 16, 
1099-1106.

470 Kerr KC, Dove CJ (2013) Delimiting shades of gray: phylogeography of the Northern Fulmar,

$471 \quad$ Fulmarus glacialis. Ecology and Evolution 3, 1915-1930.

472 Lawrence HA, Taylor GA, Millar CD, Lambert DM (2008) High mitochondrial and nuclear genetic 473 diversity in one of the world's most endangered seabirds, the Chatham Island Taiko (Pterodroma 474 magentae). Conservation Genetics 9, 1293-1301.

475 Li G, Hubert S, Bucklin K, Ribes V, Hedgecock D (2003) Characterization of 79 microsatellite DNA 476 markers in the Pacific oyster Crassostrea gigas. Molecular Ecology Notes 3, 228-232.

477 Liddle GM (1994) Interannual variation in the breeding biology of the Antarctic prion Pachyptila 478 desolata at Bird Island, South Georgia. Journal of Zoology 234, 12-139.

479 McCormack JE, Hird SM, Zellmer AJ, Carstens BC, Brumfield RT (2013) Applications of next480 generation sequencing to phylogeography and phylogenetics. Molecular Phylogenetics and Evolution 66, 526-538.

482 Moodley Y, Baumgarten I, Harley E (2006) Horse microsatellites and their amenability to 483 comparative equid genetics. Animal Genetics 37, 258-261.

484 Moore S, Sargeant L, King T, et al. (1991) The conservation of dinucleotide microsatellites among 485 mammalian genomes allows the use of heterologous PCR primer pairs in closely related species. Genomics 10, 654-660.

487 Nauta MJ, Weissing FJ (1996) Constraints on allele size at microsatellite loci: implications for genetic 488 differentiation. Genetics 143, 1021-1032.

489 Navarro J, Votier SC, Aguzzi J, et al. (2013) Ecological segregation in space, time and trophic niche 490 of sympatric planktivorous petrels. PLOS ONE 8, e62897.

491 Nunn GB, Stanley SE (1998) Body size effects and rates of cytochrome b evolution in tube-nosed seabirds. Molecular Biology and Evolution 15, 1360-1371.

493 Onley D, Scofield P (2007) Albatrosses, petrels and shearwaters of the world. Christopher Helm, $494 \quad$ London.

495 Ostrander EA, Sprague Jr GF, Rine J (1993) Identification and characterization of dinucleotide repeat 
(CA)n markers for genetic mapping in dog. Genomics 16, 207-213.

497 Ovenden J, Wust-Saucy A, Bywater R, Brothers N, White R (1991) Genetic evidence for philopatry in 498 a colonially nesting seabird, the Fairy Prion (Pachyptila turtur). Auk 108, 688-694.

499 Paetkau D, Waits LP, Clarkson PL, Craighead L, Strobeck C (1997) An empirical evaluation of 500 genetic distance statistics using microsatellite data from bear (Ursidae) populations. Genetics 147, $501 \quad 1943-1957$.

502 Patterson SA, Morris-Pocock JA, Friesen VL (2011) A multilocus phylogeny of the Sulidae (Aves: 503 Pelecaniformes). Molecular Phylogenetics and Evolution 58, 181-191.

504 Peakall R, Smouse PE (2012) GenAlEx 6.5: genetic analysis in Excel. Population genetic software for 505 teaching and research—an update. Bioinformatics 28, 2537-2539.

506 Penhallurick J, Wink M (2004) Analysis of the taxonomy and nomenclature of the Procellariiformes 507 based on complete nucleotide sequences of the mitochondrial cytochrome b gene. Emu 104, 125$508 \quad 147$.

509 Primmer CR, Painter JN, Koskinen MT, Palo JU, Merilä J (2005) Factors affecting avian cross-species 510 microsatellite amplification. Journal of Avian Biology 36, 348-360.

511 Quillfeldt P, Masello JF, McGill RAR, Adams M, Furness RW (2010) Moving polewards in winter: a 512 recent change in migratory strategy. Frontiers in Zoology 7, 15.11-15.11.

513 Quillfeldt P, Masello JF, Navarro J, Phillips RA (2013) Year-round distribution suggests spatial 514 segregation of two small petrel species in the South Atlantic. Journal of Biogeography 40, 430$515 \quad 441$.

516 Quillfeldt P, Masello JF, Strange I (2003) Breeding biology of the Thin-billed prion Pachyptila 517 belcheri at New Island, Falkland Islands, in the poor season 2002/2003: Egg desertion, breeding 518 success and chick provisioning. Polar Biology 26, 746-752.

519 Quillfeldt P, McGill RAR, Strange IJ, et al. (2008) Stable isotope analysis reveals sexual and 520 environmental variability and individual consistency in foraging of Thin-billed prions. Marine $521 \quad$ Ecology Progress Series 373, 137-148.

522 Quillfeldt P, Strange I, Masello JF (2007) Sea surface temperatures, variable food supply and 
523 behavioural buffering capacity in Thin-billed prions Pachyptila belcheri: breeding success,

524 provisioning and chick begging. Journal of Avian Biology 38, 298-308.

525 R Development Core Team (2014) R: A language and environment for statistical computing. R

$526 \quad$ Foundation for Statistical Computing, Vienna.

527 Raymond M, Rousset F (1995) GENEPOP Version 3.1d: population genetics software for exact tests

528 and ecumenism. Journal of Heredity 86, 248-249.

529 Reid K, Liddle GM, Prince PA, Croxall JP (1999) Measurement of chicks provisioning in Antarctic

530 prions Pachyptila desolata using an automated weighing system. Journal of Avian Biology 30, 127-

$531 \quad 134$

532 Rheindt FE, Austin JJ (2005) Major analytical and conceptual shortcomings in a recent taxonomic

533 revision of the Procellariiformes-a reply to Penhallurick and Wink (2004). Emu 105, 181-186.

534 Ridoux V (1994) The diets and dietary segregation of seabirds at the subantarctic Crozet Islands.

535 Marine Ornithology 22, 1-192.

536 Ryan P, Bourgeois K, Dromzée S, Dilley B (2014) The occurrence of two bill morphs of prions

537 Pachyptila vittata on Gough Island. Polar Biology 37, 727-735.

538 Schuelke M (2000) An economic method for the fluorescent labeling of PCR fragments. Nature

539 Biotechnology 18, 233-234.

540 Smith AL, Monteiro L, Hasegawa O, Friesen VL (2007) Global phylogeography of the band-rumped

541 storm-petrel (Oceanodroma castro; Procellariiformes: Hydrobatidae). Molecular Phylogenetics

542 and Evolution 43, 755-773.

543 Steeves TE, Anderson DJ, Friesen VL (2005) A role for nonphysical barriers to gene flow in the

544 diversification of a highly vagile seabird, the masked booby (Sula dactylatra). Molecular Ecology

$545 \quad \mathbf{1 4}, 3877-3887$.

546 Strange I (1980) The thin-billed prion, Pachyptila belcheri, at New Island, Falkland Islands. Gerfaut $547 \quad \mathbf{7 0}, 411-445$.

548 Sunnucks P (2000) Efficient genetic markers for population biology. Trends in Ecology \& Evolution $549 \quad \mathbf{1 5}, 199-203$. 
550 Tamura K, Stecher G, Peterson D, Filipski A, Kumar S (2013) MEGA6: Molecular Evolutionary

551 Genetics Analysis Version 6.0. Molecular Biology and Evolution 30, 2725-2729.

552 Untergasser A, Cutcutache I, Koressaar T, et al. (2012) Primer3-new capabilities and interfaces.

$553 \quad$ Nucleic Acids Research 40, e115.

554 Viot C, Jouventin P, Bried J (1993) Population genetics of southern seabirds. Marine Ornithology 21, $555 \quad 1-25$.

556 Wiley AE, Welch AJ, Ostrom PH, et al. (2012) Foraging segregation and genetic divergence between 557 geographically proximate colonies of a highly mobile seabird. Oecologia 168, 119-130.

558 Wright S (1943) Isolation by distance. Genetics 28, 114-138.

559 Wulff A, Hollingsworth PM, Haugstetter J, et al. (2012) Ten nuclear microsatellites markers cross560 amplifying in Scaevola montana and S. coccinea (Goodeniaceae), a locally common and a narrow 561 endemic plant species of ultramafic scrublands in New Caledonia. Conservation Genetics 562 Resources 4, 725-728.

563

564

565 Author Contributions

566 PQ and YM conceived and designed the study. RA, YC, RJC, M Marin, JFM, M Massaro, JN, RAP, 567 PQ, PGR, CGS and HW carried out the extensive fieldwork. MRT isolated the microsatellite 568 sequences. TLC, JFM and GKM screened the samples. JFM, YM, TLC and LC carried out the 569 bioinformatic analyses. YM, JFM and PQ drafted the manuscript. All authors reviewed the final draft 570 of the manuscript. 


\section{Data Accessibility}

573

574 DNA sequences: Genbank accessions KP122163-KP122196, KM050769 and KM050770. Shotgun

575 DNA sequence reads, 432 microsatellite genotypes at 25 loci, cytochrome $b$ alignment, distance

576 matrices and tree files: Provisional DRYAD entry doi:10.5061/dryad.rc917.

577

578

\section{Supporting Information}

580 Table S1 Phylogenetic p-distances and maximum likelihood distances (cytochrome $b$ ) in Pachyptila

581 species, blue petrels and Wilson's storm petrels

582 
Figure legends

584 Fig. 1 Observed heterozygosity (A) and proportion of missing data (B) per microsatellite locus

585 (black circles) in seven procellariiform species, against mitochondrial cytochrome $b$ phylogenetic

586 distance from the species of origin, the thin-billed prion Pachyptila belcheri. Regressions were carried

587 out separately for three different groups of species: Group one (red) includes all species (thin-billed

588 prion Pachyptila belcheri (b), Antarctic prion P. desolata (d), broad-billed prion P. vittata (v), fairy

589 prion P. turtur (t), and Salvin's prion P. salvini (s), blue petrel Halobaena caerulea (h) and Wilson's

590 storm-petrel Oceanites oceanicus(o)), Group two (green) includes Pachyptila species and Halobaena

591 caerulea only, and Group three (blue) includes only the closely related Pachyptila species. The size of

592 the circles indicates the frequency of particular proportions among microsatellite loci, as shown in the

593 figure panel. The line between both graphs represents the phylogenetic distance between each species.

594 Regression lines of mean values are shown for each group.

595

596 Fig. 2 Nuclear and mitochondrial phylogenetic relationships among thin-billed prions Pachyptila

597 belcheri, Antarctic prions $P$. desolata, broad-billed prions $P$. vittata, fairy prions $P$. turtur, Salvin's

598 prions P. salvini, blue petrels Halobaena caerulea, and Wilson's storm-petrels Oceanites oceanicus.

599 A/B. UPGMA species trees reconstructed using interspecies $F_{\mathrm{ST}}(\mathbf{A})$ and $D_{\mathrm{C}}$ distances $(\mathbf{B})$ from

600 microsatellite data sets that include null alleles (INA, in grey) and exclude null alleles (ENA, black).

601 C. Phylogeny of the mitochondrial cytochrome $b$ gene reconstructed via maximum likelihood using

602 the GTR substitution model with gamma-distributed rate heterogeneity.

603

604 Fig. 3 Mantel regressions of pairwise microsatellite distances $F_{\mathrm{ST}}(\mathbf{A})$ and $D_{\mathrm{C}}(\mathbf{B})$ against

605 mitochondrial cytochrome $b$ phylogenetic distance calculated for three groups of Procellariiform

606 species. Microsatellite genetic distances tend to lose linearity for groups that include species

607 increasingly distant to the species of origin, Pachyptila belcheri. Microsatellite distances are also

608 given including null alleles (INA, squares and solid lines) and excluding null alleles (ENA, triangles

609 and dashed lines) after Chapuis \& Estoup (2007). Species are grouped and colour-coded as in Fig. 1. 
610 Black lines describe the polynomial function that best fits the INA (solid lines) and ENA (dashed 611 lines) microsatellite distance data. 
Table 1 Locus characteristics of genetic variation at 25 newly-isolated microsatellites in the target species, the thin-billed prion Pachyptila belcheri.

\begin{tabular}{|c|c|c|c|c|c|c|c|c|c|}
\hline $\begin{array}{l}\text { Locus code } \\
\text { \& name }\end{array}$ & $\begin{array}{l}\text { Repeat } \\
\text { type }^{\S}\end{array}$ & Primer sequences $5^{\prime}-3^{\prime}$ & $\begin{array}{l}\text { Size } \\
\text { range }\end{array}$ & $N$ & $A$ & $H_{o}$ & $H_{e}$ & $F_{I S}$ & $\begin{array}{c}\mathrm{F} \\
\text { (null) }\end{array}$ \\
\hline A & $(\mathrm{AC})_{14}$ & F: GCATGTCTACAAACAAGCACG & $120-142$ & 72 & 11 & 0.764 & 0.811 & $0.058^{\mathrm{ns}}$ & 0.014 \\
\hline Pacbel_00386 & & R: TCACTGGAAACCAGAGTAGGC & & & & & & & \\
\hline $\mathrm{D}$ & $(\mathrm{AC})_{12}$ & F: AGCCATAGCTCAGTACAAGTTC & $132-170$ & 77 & 12 & 0.325 & 0.639 & $0.494^{* * *}$ & 0.203 \\
\hline Pacbel_02653 & & R: TGCAGGCATTTCAGGTTTGG & & & & & & & \\
\hline E & $(\mathrm{AC})_{14}$ & F: TAGTGGACTGGTCACAGCAC & $122-268$ & 74 & 48 & 0.392 & 0.972 & $0.599^{\text {ns }}$ & 0.293 \\
\hline Pacbel_03731 & & R: TAGCAGCTGGAGAGCATCAG & & & & & & & \\
\hline $\mathrm{F}$ & $(\mathrm{AC})_{14}$ & F: CCCATTGTCTGGGCAAAGC & $166-254$ & 47 & 19 & 0.511 & 0.815 & $0.376^{* * *}$ & 0.164 \\
\hline Pacbel_04240 & & R: GCATTCTTTGTGGGGATGGG & & & & & & & \\
\hline G & $(\mathrm{AC})_{17}$ & F: TACCAGGGACAATCTGGGTG & $158-212$ & 69 & 20 & 0.579 & 0.931 & $0.379^{* * *}$ & 0.181 \\
\hline Pacbel_04355 & & R: GGAAAAATACAGGAGATGCTTGAG & & & & & & & \\
\hline $\mathrm{H}$ & $(\mathrm{GT})_{14}$ & F: TGTCCATGAGGTCTGGAAGC & $86-106$ & 74 & 11 & 0.757 & 0.877 & $0.138^{\text {ns }}$ & 0.064 \\
\hline Pacbel_04991 & & R: GGTGGAATACAGGGATGCAC & & & & & & & \\
\hline $\mathrm{Z}$ & $(\mathrm{GT})_{15}$ & F: CGTCACTTTAATAGCGCTGGC & $148-182$ & 74 & 15 & 0.730 & 0.817 & $0.108^{\text {ns }}$ & 0.040 \\
\hline Pacbel_07265 & & R: ACCCTGATTTTCCCAGTCCG & & & & & & & \\
\hline
\end{tabular}




\begin{tabular}{|c|c|c|c|c|c|c|c|c|c|}
\hline I & $(\mathrm{TG})_{12}$ & F: TCTGGTTTCACAAATACCTACTGC & $156-172$ & 73 & 9 & 0.849 & 0.808 & $-0.052^{\text {ns }}$ & 0.000 \\
\hline Pacbel_08509 & & R: CCTAGTTTCGACACAAAGGATGG & & & & & & & \\
\hline$\tilde{\mathrm{N}}$ & $(\mathrm{GA})_{13}$ & F: TTTGGTCAATTTTCCCTCGC & $138-154$ & 74 & 8 & 0.689 & 0.690 & $0.002^{\text {ns }}$ & 0.000 \\
\hline Pacbel_08867 & & R: ACAGAAAACCAATGTTGTTAATAGG & & & & & & & \\
\hline $\mathrm{J}$ & $(\mathrm{CT})_{12}$ & F: CTGATCGGTTGTGCTCTGTG & $184-202$ & 74 & 10 & 0.757 & 0.692 & $-0.094^{\mathrm{ns}}$ & 0.000 \\
\hline Pacbel_08988 & & R: GCGGAAAGATCCTAACAAGCC & & & & & & & \\
\hline K & $(\mathrm{GT})_{12}$ & F: ATCTGCGCATGCAGTGATAG & $208-254$ & 76 & 17 & 0.829 & 0.901 & $0.080^{\text {ns }}$ & 0.034 \\
\hline Pacbel_09021 & & R: CACAGCTAGCAGCATTGACC & & & & & & & \\
\hline $\mathrm{L}$ & $(\mathrm{AC})_{12}$ & F: AACTGTTTGCTCCACACCAC & $146-170$ & 75 & 9 & 0.600 & 0.809 & $0.260^{* *}$ & 0.118 \\
\hline Pacbel_09528 & & R: ATGGCTTGGAAGTCTCCCTG & & & & & & & \\
\hline M & $(\mathrm{GT})_{13}$ & F: GCTTTATTTAAGAGCAACAAAAACTTC & $92-110$ & 73 & 10 & 0.822 & 0.830 & $0.010^{\mathrm{ns}}$ & 0.026 \\
\hline Pacbel_09957 & & R: ACAAAGCAAACCTAATCATTCCC & & & & & & & \\
\hline $\mathrm{N}$ & $(\mathrm{TG})_{12}$ & F: CAACGCGCTTTTGGTTTTGC & $102-120$ & 77 & 9 & 0.688 & 0.811 & $0.152^{\text {ns }}$ & 0.058 \\
\hline Pacbel_10033 & & R: GGCCACTCACCACAATACAAG & & & & & & & \\
\hline $\mathrm{O}$ & $(\mathrm{AC} / \mathrm{AT})_{8}$ & F: AGCTTTCTGTCTGGTAGCAC & $158-196$ & 75 & 19 & 0.720 & 0.890 & $0.192^{* *}$ & 0.092 \\
\hline Pacbel_10895 & & R: TGCTCCTGCCTAAGCTACG & & & & & & & \\
\hline
\end{tabular}




\begin{tabular}{|c|c|c|c|c|c|c|c|c|c|}
\hline S & $(\mathrm{AC})_{12}$ & F: CCAAACCCTGCCCCGATG & $92-116$ & 74 & 11 & 0.419 & 0.805 & $0.482^{* * *}$ & 0.211 \\
\hline Pacbel_12344 & & R: GCCGTGCAGACGTGAATAG & & & & & & & \\
\hline $\mathrm{T}$ & $(\mathrm{TG})_{13}$ & F: CAAGCTGGTTTTCAATGTGCC & $254-266$ & 76 & 7 & 0.697 & 0.728 & $0.042^{\text {ns }}$ & 0.020 \\
\hline Pacbel_15293 & & R: CTGAAGCATTAGCACCTGCC & & & & & & & \\
\hline Q & $(\mathrm{CA})_{13}$ & F: TTCTTGTAGCAGTAGGAGACC & $146-162$ & 75 & 8 & 0.627 & 0.674 & $0.071^{*}$ & 0.038 \\
\hline Pacbel_15327 & & R: ACCTCATGTGTAAAACCTGCC & & & & & & & \\
\hline $\mathrm{R}$ & $(\mathrm{GT})_{13}$ & F: TGAAGGTATGCCTGTCCTCC & $126-134$ & 75 & 5 & 0.640 & 0.598 & $-0.071^{\text {ns }}$ & 0.000 \\
\hline Pacbel_16671 & & R: TCGCTCCCACACACATGC & & & & & & & \\
\hline V & $(\mathrm{CA})_{12}$ & F: TGCTTTTGGACAATGTGGAGG & $100-120$ & 75 & 10 & 0.653 & 0.670 & $0.025^{\mathrm{ns}}$ & 0.026 \\
\hline Pacbel_16989 & & R: TCTGGTACACTTCTCATTTGGAC & & & & & & & \\
\hline $\mathrm{W}$ & $(\mathrm{AG})_{14}$ & F: TGCAAGGTCTTGTGATGAAGC & $142-164$ & 76 & 12 & 0.842 & 0.821 & $-0.026^{\mathrm{ns}}$ & 0.000 \\
\hline Pacbel_17529 & & R: AATGCAATTTGTCTGCGGGG & & & & & & & \\
\hline $\mathrm{X}$ & $(\mathrm{TG})_{13}$ & F: TACAACCGTTCTCCCTGTGG & $228-254$ & 75 & 12 & 0.880 & 0.828 & $-0.063^{\text {ns }}$ & 0.000 \\
\hline Pacbel_17944 & & R: GGAGAAGCAGGCAGCAATAC & & & & & & & \\
\hline $\mathrm{U}$ & $(\mathrm{GT})_{12}$ & F: ATAACCCAGTGTGATGGTGC & $204-212$ & 75 & 5 & 0.507 & 0.493 & $-0.028^{\text {ns }}$ & 0.030 \\
\hline Pacbel_17986 & & R: CACAGCTGCTTAGTGCACAG & & & & & & & \\
\hline
\end{tabular}


Pacbel_19907

$\mathrm{P}$

$(\mathrm{GT})_{12}$
$122-158$

76

Pacbel 20784

\section{R: ATGGTAGCAAACCTCCTGCC}

\footnotetext{
${ }^{\S}$ Number of repeats indicated in the subscript. Primer annealing temperature, $T a=56^{\circ} \mathrm{C}$. $N$ : number of individuals with reliable amplification. $A$ : number of alleles. $H_{o}$ : observed heterozygosity. $H_{e}$ : expected heterozygosity. $F_{I S}$ : inbreeding coefficient. The probabilities of deviation from Hardy-Weinberg equilibrium (HWE) are indicated by asterisks ( $* P<0.05,{ }^{* *} P<0.01, * * * P<0.001$, ns: not significant). F (null): null allele frequency estimate.
} 
Table 2 Cross-species genetic variation of microsatellites isolated from 25 thin-billed prions Pachyptila belcheri in Antarctic prions P. desolata (des), broadbilled prions $P$. vittata (vit), fairy prions $P$. turtur (tur), Salvin's prions $P$. salvini (sal), blue petrels Halobaena caerulea (car) and Wilson's storm-petrels Oceanites oceanicus (oce).

\begin{tabular}{|c|c|c|c|c|c|c|c|c|c|c|c|c|c|c|c|c|c|c|c|c|c|}
\hline $\begin{array}{l}\text { Locus } \\
\text { code }\end{array}$ & $\mathrm{Sp}$ & $N$ & $A$ & $H_{o}$ & $H_{e}$ & $F_{I S}$ & $\begin{array}{c}\mathrm{F} \\
\text { (null) }\end{array}$ & $\mathrm{Sp}$ & $N$ & $A$ & $H_{o}$ & $H_{e}$ & $F_{I S}$ & $\begin{array}{c}\mathrm{F} \\
\text { (null) }\end{array}$ & $\mathrm{Sp}$ & $N$ & $A$ & $H_{o}$ & $H_{e}$ & $F_{I S}$ & $\begin{array}{c}\mathrm{F} \\
\text { (null) }\end{array}$ \\
\hline \multirow[t]{2}{*}{ A } & car & 97 & 13 & 0.835 & 0.897 & $0.070^{*}$ & 0.017 & des & 79 & 13 & 0.810 & 0.862 & $0.061^{\mathrm{ns}}$ & 0.011 & tur & 33 & 2 & 0.424 & 0.403 & $-0.054^{\mathrm{ns}}$ & 0.000 \\
\hline & oce & 1 & 2 & 1 & 1 & $-1.000^{\mathrm{nc}}$ & 0.000 & vit & 117 & 11 & 0.675 & 0.828 & $0.185^{* * *}$ & 0.074 & sal & 18 & 10 & 0.778 & 0.856 & $0.093^{\text {ns }}$ & 0.033 \\
\hline \multirow[t]{2}{*}{ D } & car & 95 & 4 & 0.042 & 0.082 & $0.489^{* * *}$ & 0.088 & des & 77 & 11 & 0.468 & 0.754 & $0.381^{* * *}$ & 0.167 & tur & 33 & 5 & 0.272 & 0.525 & $0.484^{* * *}$ & 0.167 \\
\hline & oce & 6 & 2 & 0.167 & 0.167 & $0.000^{\mathrm{nc}}$ & 0.000 & vit & 115 & 9 & 0.313 & 0.642 & $0.513^{* * *}$ & 0.200 & sal & 17 & 8 & 0.471 & 0.663 & $0.297^{*}$ & 0.132 \\
\hline \multirow[t]{2}{*}{$\mathrm{E}$} & car & 95 & 13 & 0.779 & 0.795 & $0.020^{\mathrm{ns}}$ & 0.022 & des & 75 & 51 & 0.653 & 0.971 & $0.329^{* *}$ & 0.157 & tur & 1 & 1 & 0.000 & 0.000 & - & 0.001 \\
\hline & oce & 6 & 1 & 0.000 & 0.000 & - & 0.001 & vit & 111 & 39 & 0.649 & 0.951 & $0.319^{* * *}$ & 0.157 & sal & 17 & 22 & 0.588 & 0.973 & $0.403^{* * *}$ & 0.184 \\
\hline \multirow[t]{2}{*}{$\mathrm{F}$} & car & 83 & 13 & 0.313 & 0.782 & $0.601^{* * *}$ & 0.265 & des & 48 & 17 & 0.438 & 0.927 & $0.531^{* * *}$ & 0.252 & tur & 17 & 9 & 0.235 & 0.818 & $0.719^{* * *}$ & 0.311 \\
\hline & oce & 2 & 3 & 0.500 & 0.833 & $0.500^{\mathrm{ns}}$ & 0.001 & vit & 65 & 20 & 0.477 & 0.872 & $0.455^{* * *}$ & 0.204 & sal & 13 & 9 & 0.615 & 0.840 & $0.276^{*}$ & 0.104 \\
\hline \multirow[t]{2}{*}{$\mathrm{G}$} & car & 93 & 10 & 0.731 & 0.829 & $0.118^{*}$ & 0.056 & des & 76 & 20 & 0.684 & 0.930 & $0.265^{* * *}$ & 0.127 & tur & 14 & 9 & 0.429 & 0.820 & $0.487^{* * *}$ & 0.200 \\
\hline & oce & 5 & 6 & 0.400 & 0.844 & $0.556^{* *}$ & 0.189 & vit & 116 & 23 & 0.750 & 0.934 & $0.198^{* * *}$ & 0.093 & sal & 13 & 9 & 0.385 & 0.806 & $0.533^{* * *}$ & 0.203 \\
\hline $\mathrm{H}$ & car & 92 & 8 & 0.152 & 0.259 & $0.413^{* * *}$ & 0.116 & des & 78 & 10 & 0.795 & 0.893 & $0.111^{*}$ & 0.050 & tur & 33 & 4 & 0.333 & 0.526 & $0.370^{*}$ & 0.122 \\
\hline
\end{tabular}




\begin{tabular}{|c|c|c|c|c|c|c|c|c|c|c|c|c|c|c|c|c|c|c|c|c|c|}
\hline & oce & 0 & 0 & - & - & - & - & vit & 113 & 11 & 0.655 & 0.826 & $0.208^{* * *}$ & 0.094 & sal & 15 & 9 & 0.800 & 0.880 & $0.094^{\mathrm{ns}}$ & 0.043 \\
\hline \multirow[t]{2}{*}{ Z } & car & 85 & 28 & 0.635 & 0.947 & $0.331^{* * *}$ & 0.160 & des & 72 & 15 & 0.694 & 0.785 & $0.116^{\mathrm{ns}}$ & 0.057 & tur & 21 & 6 & 0.619 & 0.560 & $-0.109^{\mathrm{ns}}$ & 0.000 \\
\hline & oce & 5 & 5 & 0.400 & 0.844 & $0.556^{*}$ & 0.203 & vit & 103 & 14 & 0.709 & 0.777 & $0.088^{* *}$ & 0.033 & sal & 16 & 7 & 0.625 & 0.756 & $0.178^{\mathrm{ns}}$ & 0.048 \\
\hline \multirow[t]{2}{*}{ I } & car & 95 & 13 & 0.832 & 0.846 & $0.017^{\mathrm{ns}}$ & 0.015 & des & 75 & 11 & 0.720 & 0.785 & $0.083^{*}$ & 0.027 & tur & 16 & 5 & 0.438 & 0.688 & $0.371^{*}$ & 0.156 \\
\hline & oce & 6 & 2 & 0.167 & 0.167 & $0.000^{\mathrm{nc}}$ & 0.000 & vit & 111 & 12 & 0.730 & 0.756 & $0.034^{* *}$ & 0.032 & sal & 11 & 6 & 0.636 & 0.805 & $0.218^{\mathrm{ns}}$ & 0.073 \\
\hline \multirow[t]{2}{*}{$\tilde{\mathrm{N}}$} & car & 82 & 10 & 0.841 & 0.795 & $-0.059^{\text {ns }}$ & 0.000 & des & 78 & 9 & 0.590 & 0.664 & $0.113^{\text {ns }}$ & 0.041 & tur & 26 & 6 & 0.577 & 0.728 & $0.211^{* *}$ & 0.060 \\
\hline & oce & 6 & 2 & 0.500 & 0.409 & $-0.250^{\mathrm{ns}}$ & 0.000 & vit & 106 & 5 & 0.623 & 0.630 & $0.012^{\text {ns }}$ & 0.014 & sal & 17 & 6 & 0.824 & 0.745 & $-0.109^{\text {ns }}$ & 0.000 \\
\hline \multirow[t]{2}{*}{$\mathrm{J}$} & car & 89 & 12 & 0.348 & 0.859 & $0.596^{* * *}$ & 0.272 & des & 77 & 9 & 0.792 & 0.697 & $-0.138^{\mathrm{ns}}$ & 0.000 & tur & 33 & 2 & 0.030 & 0.088 & $0.660^{*}$ & 0.105 \\
\hline & oce & 6 & 2 & 0.500 & 0.409 & $-0.250^{\mathrm{ns}}$ & 0.000 & vit & 113 & 6 & 0.575 & 0.635 & $0.094^{* *}$ & 0.040 & sal & 11 & 4 & 0.364 & 0.688 & $0.484^{\mathrm{ns}}$ & 0.190 \\
\hline \multirow[t]{2}{*}{ K } & car & 95 & 22 & 0.821 & 0.913 & $0.101^{*}$ & 0.049 & des & 75 & 22 & 0.907 & 0.893 & $-0.015^{\mathrm{ns}}$ & 0.000 & tur & 10 & 6 & 0.600 & 0.832 & $0.290^{\mathrm{ns}}$ & 0.133 \\
\hline & oce & 6 & 2 & 0.167 & 0.167 & $0.000^{\mathrm{nc}}$ & 0.000 & vit & 112 & 18 & 0.848 & 0.911 & $0.069^{* *}$ & 0.019 & sal & 17 & 12 & 0.882 & 0.895 & $0.014^{\mathrm{ns}}$ & 0.000 \\
\hline \multirow[t]{2}{*}{$\mathrm{L}$} & car & 95 & 9 & 0.589 & 0.675 & $0.127^{*}$ & 0.061 & des & 72 & 14 & 0.653 & 0.814 & $0.199^{* *}$ & 0.079 & tur & 32 & 7 & 0.375 & 0.609 & $0.388^{* * *}$ & 0.151 \\
\hline & oce & 1 & 1 & 0.000 & 0.000 & - & 0.001 & vit & 114 & 13 & 0.500 & 0.640 & $0.219^{* * *}$ & 0.079 & sal & 11 & 5 & 0.636 & 0.775 & $0.186^{\mathrm{ns}}$ & 0.050 \\
\hline \multirow[t]{2}{*}{ M } & car & 85 & 2 & 0.059 & 0.057 & $-0.024^{\mathrm{ns}}$ & 0.000 & des & 78 & 9 & 0.679 & 0.826 & $0.179^{* * *}$ & 0.062 & tur & 29 & 5 & 0.655 & 0.662 & $0.011^{\mathrm{ns}}$ & 0.031 \\
\hline & oce & 4 & 4 & 0.250 & 0.821 & $0.727^{*}$ & 0.278 & vit & 116 & 7 & 0.431 & 0.674 & $0.362^{* * *}$ & 0.152 & sal & 15 & 7 & 0.533 & 0.766 & $0.311^{\mathrm{ns}}$ & 0.098 \\
\hline \multirow[t]{2}{*}{$\mathrm{N}$} & car & 95 & 9 & 0.568 & 0.842 & $0.326^{* * *}$ & 0.151 & des & 78 & 9 & 0.679 & 0.825 & $0.178^{*}$ & 0.075 & tur & 35 & 5 & 0.429 & 0.737 & $0.422^{* * *}$ & 0.170 \\
\hline & oce & 5 & 4 & 0.600 & 0.644 & $0.077^{\mathrm{ns}}$ & 0.000 & vit & 117 & 10 & 0.752 & 0.802 & $0.063^{\text {ns }}$ & 0.012 & sal & 14 & 6 & 0.571 & 0.815 & $0.307^{\mathrm{ns}}$ & 0.119 \\
\hline
\end{tabular}




\begin{tabular}{|c|c|c|c|c|c|c|c|c|c|c|c|c|c|c|c|c|c|c|c|c|c|}
\hline \multirow[t]{2}{*}{$\mathrm{O}$} & car & 92 & 36 & 0.793 & 0.946 & $0.162^{* *}$ & 0.068 & des & 78 & 17 & 0.487 & 0.866 & $0.439^{* * *}$ & 0.202 & tur & 10 & 4 & 0.100 & 0.363 & $0.735^{* *}$ & 0.192 \\
\hline & oce & 4 & 5 & 0.250 & 0.893 & $0.750^{*}$ & 0.300 & vit & 112 & 21 & 0.295 & 0.868 & $0.662^{* * *}$ & 0.306 & sal & 16 & 11 & 0.438 & 0.855 & $0.496^{* * *}$ & 0.209 \\
\hline \multirow[t]{2}{*}{ S } & car & 90 & 7 & 0.367 & 0.729 & $0.499^{* * *}$ & 0.207 & des & 65 & 11 & 0.662 & 0.838 & $0.212^{*}$ & 0.088 & tur & 19 & 5 & 0.421 & 0.616 & $0.322^{*}$ & 0.149 \\
\hline & oce & 5 & 1 & 0.000 & 0.000 & - & 0.001 & vit & 104 & 12 & 0.587 & 0.839 & $0.302^{* * *}$ & 0.133 & sal & 14 & 8 & 0.714 & 0.796 & $0.107^{\text {ns }}$ & 0.005 \\
\hline \multirow[t]{2}{*}{$\mathrm{T}$} & car & 96 & 7 & 0.708 & 0.730 & $0.030^{\text {ns }}$ & 0.020 & des & 79 & 9 & 0.759 & 0.774 & $0.019^{\text {ns }}$ & 0.005 & tur & 13 & 3 & 0.538 & 0.495 & $-0.091^{\text {ns }}$ & 0.000 \\
\hline & oce & 6 & 1 & 0.000 & 0.000 & - & 0.001 & vit & 114 & 6 & 0.640 & 0.676 & $0.053^{\text {ns }}$ & 0.012 & sal & 16 & 6 & 0.750 & 0.776 & $0.035^{\mathrm{ns}}$ & 0.000 \\
\hline \multirow[t]{2}{*}{ Q } & car & 89 & 14 & 0.798 & 0.877 & $0.091^{\text {ns }}$ & 0.040 & des & 76 & 12 & 0.711 & 0.756 & $0.061^{\mathrm{ns}}$ & 0.000 & tur & 22 & 5 & 0.545 & 0.636 & $0.146^{\text {ns }}$ & 0.053 \\
\hline & oce & 1 & 1 & 0.000 & 0.000 & - & 0.001 & vit & 113 & 10 & 0.726 & 0.737 & $0.015^{\mathrm{ns}}$ & 0.005 & sal & 17 & 8 & 0.647 & 0.775 & $0.170^{\text {ns }}$ & 0.042 \\
\hline \multirow[t]{2}{*}{$\mathrm{R}$} & car & 96 & 5 & 0.219 & 0.240 & $0.091^{\text {ns }}$ & 0.018 & des & 78 & 9 & 0.372 & 0.394 & $0.056^{\text {ns }}$ & 0.004 & tur & 21 & 2 & 0.095 & 0.093 & $-0.026^{\mathrm{ns}}$ & 0.000 \\
\hline & oce & 6 & 1 & 0.000 & 0.000 & - & 0.001 & vit & 99 & 6 & 0.485 & 0.514 & $0.057^{* *}$ & 0.046 & sal & 16 & 6 & 0.313 & 0.512 & $0.398^{* *}$ & 0.126 \\
\hline \multirow[t]{2}{*}{ V } & car & 95 & 3 & 0.158 & 0.148 & $-0.070^{\mathrm{ns}}$ & 0.000 & des & 75 & 12 & 0.720 & 0.720 & $0.000^{\mathrm{ns}}$ & 0.000 & tur & 33 & 10 & 0.636 & 0.734 & $0.135^{\mathrm{ns}}$ & 0.053 \\
\hline & oce & 6 & 1 & 0.000 & 0.000 & - & 0.001 & vit & 109 & 10 & 0.780 & 0.747 & $-0.045^{\mathrm{ns}}$ & 0.000 & sal & 14 & 7 & 0.643 & 0.794 & $0.196^{\mathrm{ns}}$ & 0.087 \\
\hline \multirow[t]{2}{*}{ W } & car & 89 & 14 & 0.888 & 0.852 & $-0.042^{\text {ns }}$ & 0.000 & des & 78 & 12 & 0.795 & 0.827 & $0.040^{\text {ns }}$ & 0.026 & tur & 30 & 10 & 0.733 & 0.879 & $0.168^{* * *}$ & 0.082 \\
\hline & oce & 6 & 3 & 0.500 & 0.439 & $-0.154^{\mathrm{ns}}$ & 0.000 & vit & 117 & 11 & 0.795 & 0.850 & $0.065^{*}$ & 0.026 & sal & 18 & 8 & 1.000 & 0.835 & $-0.205^{\mathrm{ns}}$ & 0.000 \\
\hline \multirow[t]{2}{*}{ X } & car & 94 & 10 & 0.617 & 0.746 & $0.173^{* * *}$ & 0.082 & des & 79 & 13 & 0.810 & 0.866 & $0.064^{\mathrm{ns}}$ & 0.027 & tur & 33 & 8 & 0.394 & 0.505 & $0.222^{* * *}$ & 0.103 \\
\hline & oce & 6 & 4 & 0.500 & 0.455 & $-0.111^{\text {ns }}$ & 0.000 & vit & 112 & 12 & 0.705 & 0.804 & $0.123^{*}$ & 0.050 & sal & 16 & 8 & 0.938 & 0.857 & $-0.098^{\mathrm{ns}}$ & 0.000 \\
\hline
\end{tabular}




\begin{tabular}{|c|c|c|c|c|c|c|c|c|c|c|c|c|c|c|c|c|c|c|c|c|c|}
\hline \multirow[t]{2}{*}{$\mathrm{U}$} & car & 97 & 4 & 0.082 & 0.080 & $-0.025^{\mathrm{ns}}$ & 0.000 & des & 77 & 6 & 0.571 & 0.500 & $-0.143^{\mathrm{ns}}$ & 0.000 & tur & 33 & 3 & 0.182 & 0.224 & $0.190^{\mathrm{ns}}$ & 0.063 \\
\hline & oce & 6 & 1 & 0.000 & 0.000 & - & 0.001 & vit & 117 & 4 & 0.419 & 0.469 & $0.107^{\mathrm{ns}}$ & 0.021 & sal & 16 & 5 & 0.625 & 0.558 & $-0.124^{\mathrm{ns}}$ & 0.000 \\
\hline \multirow[t]{2}{*}{ Y } & car & 94 & 5 & 0.511 & 0.528 & $0.033^{\mathrm{ns}}$ & 0.006 & des & 72 & 5 & 0.514 & 0.520 & $0.013^{\mathrm{ns}}$ & 0.000 & tur & 17 & 3 & 0.176 & 0.266 & $0.343^{\mathrm{ns}}$ & 0.093 \\
\hline & oce & 0 & 0 & - & - & - & - & vit & 104 & 7 & 0.692 & 0.650 & $-0.066^{\mathrm{ns}}$ & 0.000 & sal & 11 & 3 & 0.636 & 0.636 & $0.000^{\mathrm{ns}}$ & 0.040 \\
\hline \multirow[t]{2}{*}{$\mathrm{P}$} & car & 90 & 10 & 0.244 & 0.311 & $0.214^{* *}$ & 0.081 & des & 75 & 15 & 0.387 & 0.854 & $0.549^{* * *}$ & 0.250 & tur & 25 & 10 & 0.160 & 0.839 & $0.813^{* * *}$ & 0.364 \\
\hline & oce & 6 & 3 & 0.500 & 0.439 & $-0.154^{\mathrm{ns}}$ & 0.000 & vit & 117 & 14 & 0.504 & 0.765 & $0.341^{* * *}$ & 0.152 & sal & 14 & 8 & 0.429 & 0.865 & $0.514^{* *}$ & 0.228 \\
\hline
\end{tabular}

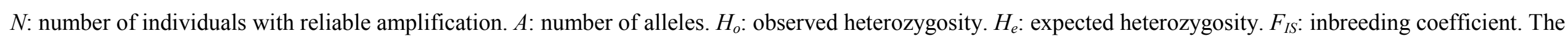

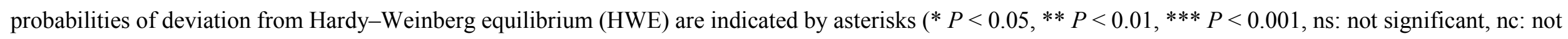
calculated). F (null): null allele frequency estimate. 
Table 3 Fitting linear and polynomial functions to variance in microsatellite distance statistics across seven sub-Antarctic seabird species.

\begin{tabular}{ccccccc}
\hline Statistic & $\begin{array}{c}\text { Best fit } \\
\text { linear function }\end{array}$ & $\begin{array}{c}\text { AIC } \\
\text { linear }\end{array}$ & $\begin{array}{c}\text { Best fit } \\
\text { polynomial function }\end{array}$ & $\begin{array}{c}\text { AIC } \\
\text { poly. }\end{array}$ & $\begin{array}{c}\text { delta } \\
\text { AIC }\end{array}$ & $P$ \\
\hline$F_{\text {ST }}$ INA & $\mathrm{y}=2.325 \mathrm{x}+0.024$ & -67.2 & $\mathrm{y}=-12.599 \mathrm{x}^{2}+4.285 \mathrm{x}-0.015$ & -72.5 & 5.3 & 0.013 \\
$F_{\text {ST }}$ ENA & $\mathrm{y}=2.437 \mathrm{x}+0.014$ & -72.5 & $\mathrm{y}=-9.259 \mathrm{x}^{2}+3.877 \mathrm{x}-0.014$ & -75.3 & 2.8 & 0.045 \\
$D_{\mathrm{C}}$ INA & $\mathrm{y}=2.826 \mathrm{x}+0.314$ & -53.4 & $\mathrm{y}=-19.726 \mathrm{x}^{2}+5.894 \mathrm{x}+0.253$ & -61.3 & 7.9 & 0.004 \\
$D_{\mathrm{C}}$ ENA & $\mathrm{y}=2.802 \mathrm{x}+0.312$ & -56.3 & $\mathrm{y}=-17.195 \mathrm{x}^{2}+5.477 \mathrm{x}+0.259$ & -62.5 & 6.3 & 0.009 \\
\hline
\end{tabular}



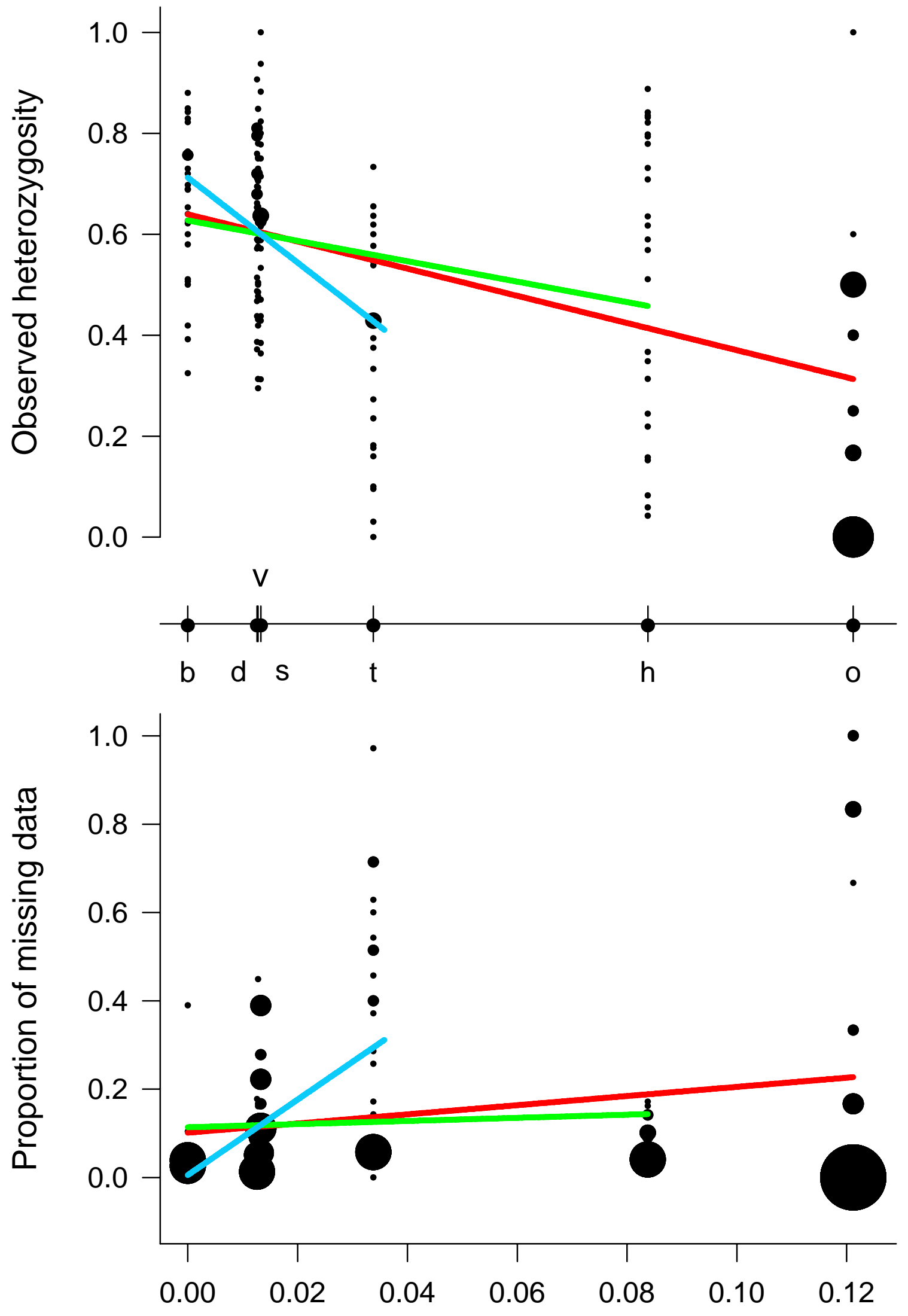

Frequency of proportions

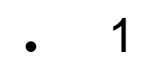

- 2

- 4

- 6

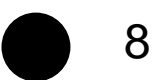

Phylogenetic p-distance (cyt b) 


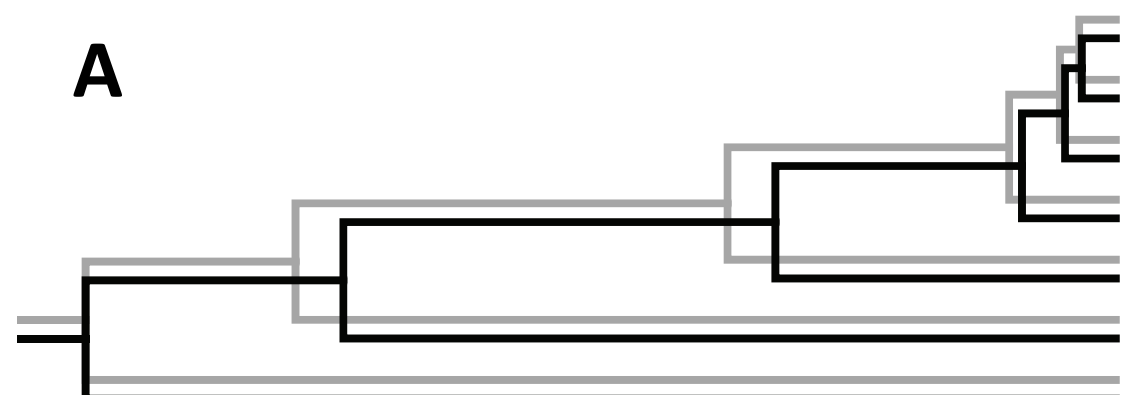

P. desolata

$P$. salvini

P. belcheri

P. vittata

P. turtur

H. caerulea

O. oceanicus
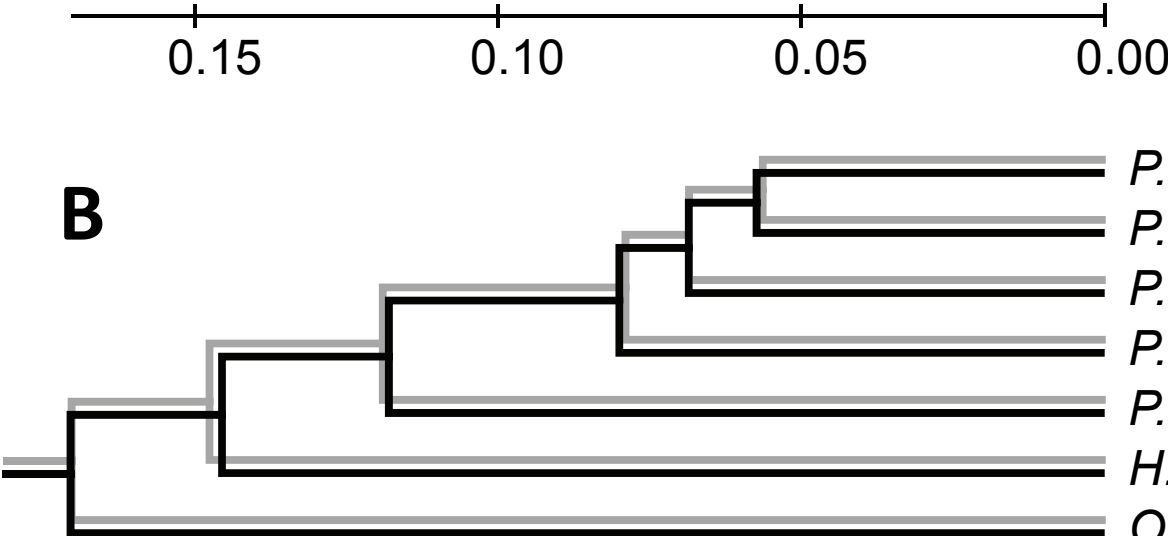

P. belcheri

P. desolata

P. vittata

P. salvini

P. turtur

H. caerulea

O. oceanicus

\begin{tabular}{lllllll}
\hline & 1 & $\prime$ & & $\prime$ & & \\
0.30 & 0.25 & 0.20 & 0.15 & 0.10 & 0.05 & 0.00
\end{tabular}

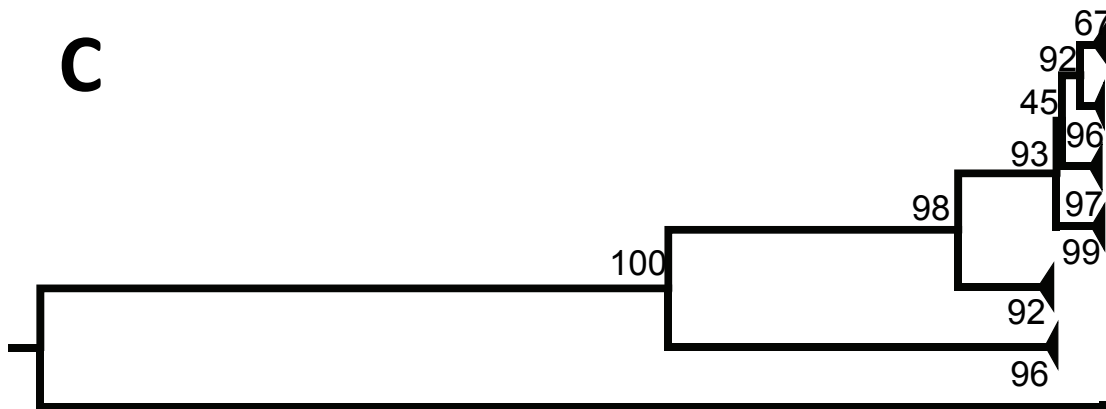

P. desolata P. salvini

$P$. vittata

P. belcheri

$P$. turtur

H. caerulea

O. oceanicus

0.05 

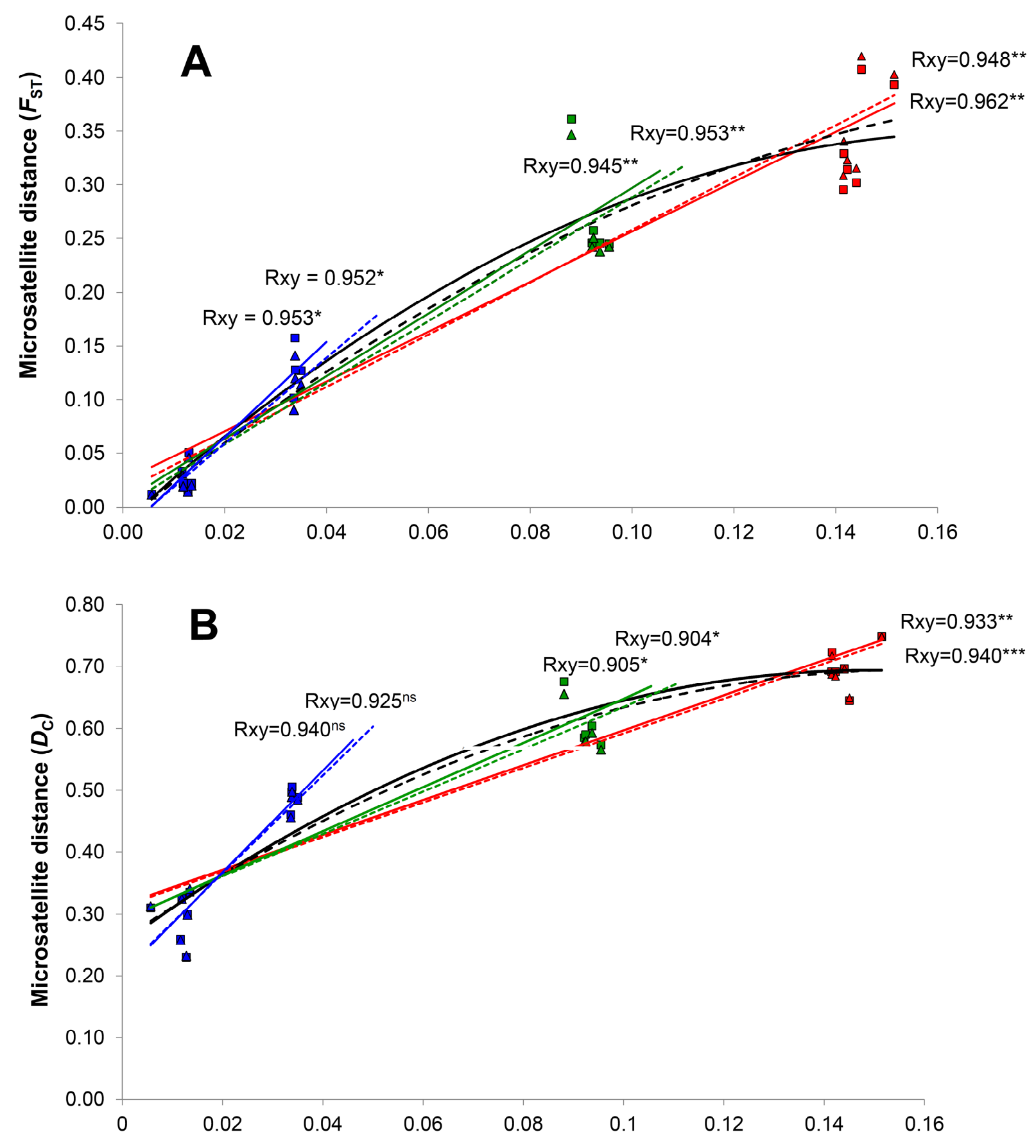

Maximum likelihood distance (cyt $b$ )

- All species (INA)

- Halobaena and Pachyptila only (INA)

- Pachyptila only (INA)

_Linear (All species (INA))

---- Linear (All species (ENA))

_ Linear (Halobaena and Pachyptila only (INA))

_Linear (Pachyptila only (INA)) $\triangle$ All species (ENA)

$\Delta$ Halobaena and Pachyptila only (ENA)

\ Pachyptila only (ENA)

—Polynomial (INA)

- - Polynomial (ENA)

---- Linear (Halobaena and Pachyptila only (ENA))

----- Linear (Pachyptila only (ENA)) 